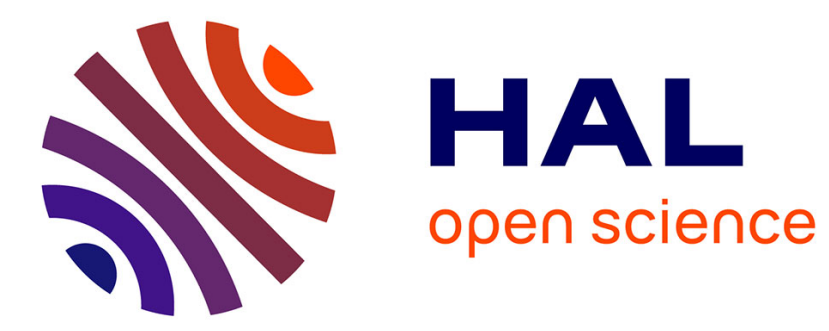

\title{
Endogenous Mergers and Cost Heterogeneity
}

Laurent Granier

\section{To cite this version:}

Laurent Granier. Endogenous Mergers and Cost Heterogeneity. Applied Economics, 2008, 40 (14), pp.1865-1871. 10.1080/00036840600905258 . hal-00582030

\section{HAL Id: hal-00582030 \\ https://hal.science/hal-00582030}

Submitted on 1 Apr 2011

HAL is a multi-disciplinary open access archive for the deposit and dissemination of scientific research documents, whether they are published or not. The documents may come from teaching and research institutions in France or abroad, or from public or private research centers.
L'archive ouverte pluridisciplinaire HAL, est destinée au dépôt et à la diffusion de documents scientifiques de niveau recherche, publiés ou non, émanant des établissements d'enseignement et de recherche français ou étrangers, des laboratoires publics ou privés. 


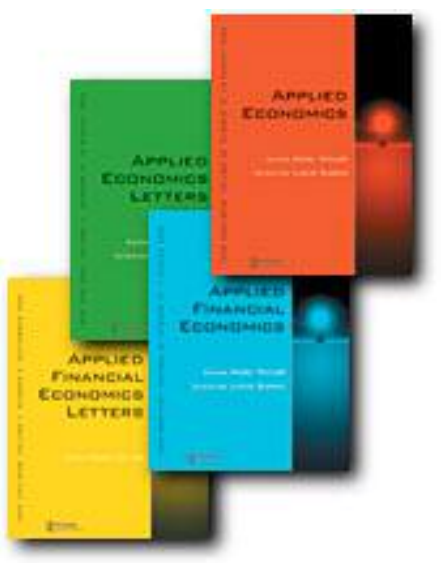

\section{Endogenous Mergers and Cost Heterogeneity}

\begin{tabular}{|r|l|}
\hline Journal: & Applied Economics \\
\hline Manuscript ID: & APE-05-0706.R1 \\
\hline Journal Selection: & Applied Economics \\
\hline JEL Code: & $\begin{array}{l}\text { L12 - Monopoly|Monopolization Strategies < L1 - Market Structure, } \\
\text { Organization, L41 - Monopolization|Horizontal Anticompetitive } \\
\text { Practices < L4 - Antitrust Policy < L - Industrial Organization }\end{array}$ \\
\hline Keywords: & $\begin{array}{l}\text { Competition Policy, Cost Heterogeneity, Endogenous Mergers, } \\
\text { Monopolization }\end{array}$ \\
\hline
\end{tabular}

powered by ScholarOne

Manuscript Central ${ }^{\text {M }}$ 


\title{
Endogenous Mergers and Cost
}

\section{Heterogeneity}

\author{
Laurent Granier ${ }^{1}$ \\ L.A.S.E.R.-C.R.E.D.E.N. \\ University of Montpellier $1^{2}$
}

\begin{abstract}
The objective of this paper is to analyze the effect of firms' heterogeneity on their incentives to merge. To reach this target, merger decisions are modelled as endogenous. To simplify the analysis, we focus on the extreme case where merger leads to monopolization. Kamien and Zang (1990 and 1993) give monopolization conditions in static and dynamic acquisition games. Introducing cost heterogeneity in a n-firm industry, we provide more general monopolization conditions. Indeed, we show that any industry can be monopolized if cost heterogeneity is large enough. This result provides new informations to competition authorities on concentration possibilities and allows them to focus particularly on some industries.

JEL classification: L12; L41.
\end{abstract}

Keywords: Competition Policy, Cost Heterogeneity, Endogenous Mergers, Monopolization.

\footnotetext{
${ }^{1}$ Email: laurent.granier@univ-montp1.fr

${ }^{2}$ University of Montpellier 1: CS 7970634960 Montpellier Cedex 2 France.
} 


\section{Introduction}

The literature on horizontal mergers presents different types of analyses. Williamson (1968) shows that mergers have positive effects on welfare. But, this idea has often been contradicted. In this sense, competition authorities develop a good tool to monitor mergers. Studies suggest, as Charléty and Souam (2002), that ex-ante competition policy is more efficient and less expensive than ex-post. For this reason, analyses of merger conditions have appeared. For example, Salant, Switzer, and Reynolds (1983) study incentives to participate to mergers, by considering them as exogenous phenomena. Finally, to take into account decisions of firms' owners in merger processes, other authors (for instance Fridolfsson and Stennek [2005], Horn and Persson [2001]) have modelled endogenous merger processes. The main interest of these studies is to give informations to competition authorities on concentration possibilities and allows them to focus particularly on some industries.

Using the same framework, we try to answer a related question: what are merger processes conditions? Because merger decisions are endogenous in our model, we simplify the analysis by concentrating on monopolization processes. In the same way, Kamien and Zang $(1990,1993)$ considered two acquisition games in which symmetric firms compete "à la Cournot" and a single owner is able to purchase firms. They show on the one hand that, in a static game, monopolization is not possible in industries larger than duopolies. On the other hand, they show in a dynamic game that monopolization is not possible in 
industries larger than triopolies. Our model is based on the Kamien and Zang models (1990 and 1993) and shows that firms' heterogeneity increases the incentives to merge.

Following Gowrisankaran and Holmes (2004) we introduce cost heterogeneity between firms and concentrate on the merger incentives of the most efficient firm. Gowrisankaran and Holmes (2004) present a complex model using Markov Perfect Equilibrium concept. This model allows them to take into account investment decisions but it cannot be solved analytically. For this reason, we present a model without investment decisions. We find that monopolization conditions are then less restrictive. Indeed, this paper presents static and dynamic acquisition games in which the owner of the most efficient firm attempts to buy the other firms. We find that monopolization is always possible if cost heterogeneity is large enough. This result supports the "takeover waves" explanation of Fauli-Oller (2000) based on cost asymmetries. But Faulli-Oller (2000) considered a four-firm industry in which two firms are more efficient than the two others. Moreover, he underlines the role of negative shocks of demand on the profitability of takeovers. Assuming a low realization of demand, we propose to focus on a main topic: monopolization of a n-firm industry in which a single firm is more efficient than others.

The rest of the paper is organized as follow. In the second section, we present the static acquisition game. The third section is dedicated to the dynamic game. Finally, we conclude on contributions of the cost heterogeneity assumption. 


\section{The static game}

We focus on $n$-firm industries and we define by $N=\{1,2, ., i, . ., n\}$ the initial set of firms ${ }^{3}$. A firm must be sold in one part. Note that each firm is initially owned by an individual owner but if an owner bought other firms, he adopts a behaviour corresponding to a single entity. Note $Q=\sum_{i=1}^{n} q_{i}$ with $q_{i}$ the individual output of firm $i$.

The inverse demand function for the unique good is given by $P(Q)=1-Q$. We note the linear cost function of each firm $C\left(q_{i}\right)=c_{i} q_{i}$ with $i \in\{1,2, \ldots, n\}$ - $c_{i}$ can take two values: $c_{1}$ for the most efficient firm and $c$ for the other symmetric firms. Note that $c_{i} \in[0,1] \forall i \in\{1,2, \ldots, n\}$ and $c_{1} \leq c$.

We consider a three stage game: in the first stage, the owner of the most efficient firm ${ }^{4}$ makes bids for the other firms and owners of the other firms give an asking price for their own firm. In the second stage, the dominant firm decides how many firms he wants to operate. In the third one, Cournot competition takes place in the industry.

We must note that this game is a game with perfect information. For example, firms are totally informed of consequences of buying another firm, or conversely, to be purchased. Hence, an inefficient firm cannot earn more than a

\footnotetext{
${ }^{3}$ It's assumed that entries in the industry are not allowed.

${ }^{4} \mathrm{We}$ assume that the firm 1 is the only one who makes bids. Even if we can prove that an inefficient firm have the same incentive to monopolize the industry, firm 1 seems closer to realize this monopolization. Indeed, his previous profits are higher because of his low cost. It could always spend more than inefficient firms if these last were allowed to make bids.
} 
duopoly profit if it unilaterally deviates from its selling. Therefore, it cannot ask for more than this price. Secondly, the first firm earns more by purchasing a firm, spending the duopoly profit of this last, rather than by not purchasing this firm.

\section{Consider the three stages of the game:}

In the first one, firm 1 makes bids for all other firms. Simultaneously, other owners give an asking price for their own firms. Note $B=\left(b_{2}, \ldots, b_{i}, \ldots, b_{n}\right) \in \mathrm{R}$ the vector of bids announced by the first owner. The $b_{i}$ bid is the bid for the $i^{\text {th }}$ firm. Note $O=\left(o_{2}, \ldots, o_{i}, \ldots, o_{n}\right) \in \mathrm{R}$ the vector of asking prices announced by the owners 2 to $n$. The $o_{i}$ asking price correspond to the $i^{\text {th }}$ firm asking price. We note $K$ the number of firms owned by the first owner after this stage. In the second stage, the first owner decides how many firms he is going to operate among his $K$ firms. As cost functions are linear, he always decides to operate only the most efficient. Therefore, it is not necessary to analyse this stage. The question is to know how many firms remain after the dominant firm buys out competitive fringe firms. In the third stage, owners simultaneously decide output levels.

In this game, we characterize monopoly Nash Equilibrium in pure strategies ${ }^{5}$. Strategies are defined, for each owner, by a bid vector and by an

\footnotetext{
${ }^{5}$ To simplify the analysis and concentrate on the emergence of monopoly, we exclude acquisition path without monopolization. Nevertheless, given that the level of cost heterogeneity, other equilibria than monopoly can be more profitable.
} 
output quantity. Owner's outcome is the sum of profits and transaction cash flow. There is monopolization if and only if the first owner's monopoly profit minus acquisition costs exceeds his opportunity cost. We analyze this payoff in order to determine if the dominant firm is able to make bids to buy out all the competitive fringe firms. As a firm unilaterally refusing to be sold potentially earns a duopoly profit, the acquisition cost is, for each firm, the profit earned in competition with the first firm. The behaviour of the firms asking for a duopoly profit can be seen as an hold up mechanism. The opportunity cost is the profit of the first firm if it does not buy any firm.

We note $\pi_{i}^{n}\left(c_{1}, c\right)$ with $i \in[1,2], n \in[2,+\infty[$ the profit of firm $i$ in a nfirm industry with $c_{1}$ the marginal cost of firm 1 and $c$ the marginal cost of the $n-1$ other firms. Profits of the firm 1 are given by $i=1$. Given that every other firm is symmetric, firms profits are given by $i=2$. Given individual marginal costs $C_{i}$ and the linear inverse demand $P(Q)=1-Q$, then firms profits in the nfirm problem are given by Letho and Tombak (1998):

$$
\frac{\left(1-n c_{i}+\sum_{j \neq i} c_{j}\right)^{2}}{(n+1)^{2}}
$$

We can establish the monopoly profit of the firm 1 :

$$
\pi_{1}^{1}\left(c_{1}\right)=\frac{\left(1-c_{1}\right)^{2}}{4}
$$

We can give the opportunity cost of the firm 1 (the profit realized by this firm if it buys no firm): 


$$
\pi_{1}^{n}\left(c_{1}, c\right)=\frac{\left(1-n c_{1}+(n-1) c\right)^{2}}{(n+1)^{2}}
$$

Finally, the acquisition cost of an inefficient firm takes the following form:

$$
\pi_{2}^{2}\left(c_{1}, c\right)=\frac{\left(1-2 c+c_{1}\right)^{2}}{9}
$$

If $n$ firms are initially present in the industry, the monopolization condition is:

$$
\pi_{1}^{1}\left(c_{1}\right)-(n-1) \pi_{2}^{2}\left(c_{1}, c\right) \geq \pi_{1}^{n}\left(c_{1}, c\right)
$$

(2) holds if (3) is checked:

$$
c \geq \underline{c}\left(n, c_{1}\right)
$$

with

$$
\underline{c}\left(n, c_{1}\right)=\frac{1}{2} \frac{\left(4 c_{1} n^{2}+35 c_{1} n+13 c_{1}+4 n^{2}-23-n\right)}{\left(4 n^{2}+17 n-5\right)}
$$

Lemma 1 Let $c_{1} \in[0,1]$ and $n \in[2,+\infty[$, then It always exists a $c \in[0,1]$ verifying $\underline{c}\left(n, c_{1}\right) \leq c \leq \frac{1+c_{1}}{2}$.

Proof To exclude negative profits, sustainable industry conditions must also be checked. One of these conditions is $c \leq \frac{1+c_{1}}{2}$. Indeed, firm 1 is the only one to produce if and only if $c \geq \frac{1+c_{1}}{2}$. But, two other sustainable industry conditions are assumed in our model, that are: $c \in[0,1]$ and $c_{1} \in[0,1]$. Thereby, $\frac{1+c_{1}}{2} \leq 1$. As, $\forall c_{1} \in[0,1]$ and $\forall n \in\left[2,+\infty\left[, \underline{c}\left(n, c_{1}\right) \leq \frac{1+c_{1}}{2}\right.\right.$, we can state that it always exists $c \in[0,1]$ which respects $\underline{c}\left(n, c_{1}\right) \leq c \leq \frac{1+c_{1}}{2} \leq 1$. 
Proposition 1 Let $c \in[0,1], \quad c_{1} \in[0,1]$ and $n \in[2,+\infty[$, then $a$ monopolization path of a $n$-firm industry exists if and only if $c \geq \underline{c}\left(n, c_{1}\right)$.

This result is intuitive because monopoly profits are more sensitive to efficiency than profits in any other market structure. Indeed we have shown that monopolization is possible for every size of industry if the cost heterogeneity is large enough.

Note that $\forall n>1, \forall c_{1} \in[0,1], \frac{\partial \underline{\underline{c}}\left(n, c_{1}\right)}{\partial n}>0$. Subsequently, the larger the industry is, the stronger the cost heterogeneity must be to have monopolization.

In the symmetric case, that is for $c_{1}=c$, we find, like Kamien and Zang (1990), that industries larger than two firms cannot be monopolized.

\section{The dynamic game:}

We have shown that monopolization is feasible in large industries if the cost structure is heterogeneous enough. If the game takes place in several rounds, we see that cost structure conditions are modified. Indeed, to buy out firms become less expensive in the dynamic game because of the disappearance of the hold up mechanism previously identified. The sellers cannot ask for duopoly profits as the monopolization can appear in several rounds and not only in the next round. Consequently, if the discount factor is 1 , that is without actualization rate, every industry monopolized in the static game is also monopolized in several rounds. 
We show that a dynamic analysis increases the number of monopolization opportunities even if the discount factor is smaller than 1 . This demonstration provides the proof that dynamic modelling makes monopolization easier.

Keeping the same assumptions and taking into account that the number of firms can decrease between two rounds, we extend the three stages of the static game on an infinite horizon. Note that game participants are perfectly informed $^{6}$. We note $\delta=\frac{1}{1+r}$ the discount factor, where $r$ is the interest rate. When it is not specified, conditions and propositions are established with $\delta$ and $c_{1}$ between 0 and 1.

In the two next sections, we provide two illustrations of the dynamic game because the n-firm generalization is very complex. First, we study the case of a three-firm industry and second we analyze the case of a four-firm industry.

\subsection{With a three-firm industry:}

We exclude the one round case because it is equivalent to the static monopolization case.

We assume that there are two rounds because it is easy to prove that a path with more than two rounds does not provide an advantage to the first owner ${ }^{7}$. Thus, one firm is purchased in the first round and another is bought in the next round.

\footnotetext{
${ }^{6}$ In particular, the remaining firms are informed of the previous buying.

${ }^{7}$ To buy one firm per round is the most advantageous path to reach monopolization (see Kamien and Zang (1993)).
} 
Again, we must analyze conditions of these two acquisitions. Hence a backward induction arguing is followed, that is:

\section{Second round:}

After the second stage, if the dominant firm monopolized the industry, it earns an infinite monopoly profit flow.

To obtain this payoff, it must pay the acquisition cost of the remaining firm. As this last firm could earn a duopoly profit by deviating from its own sell off, the firm 1 will have to pay this duopoly profit to monopolize the industry.

The dominant firm could earn an infinite flow of duopoly profits by paying no firm. Therefore, when this last one monopolizes the industry, its opportunity cost is this infinite flow of duopoly profit (proof in appendix A):

$$
\frac{\pi_{1}^{1}\left(c_{1}\right)}{(1-\delta)}-\frac{\pi_{2}^{2}\left(c_{1}, c\right)}{(1-\delta)} \geq \frac{\pi_{1}^{2}\left(c_{1}, c\right)}{(1-\delta)}
$$

(4) holds if (5) is checked:

$$
\frac{11}{10} c_{1}-\frac{1}{10} \leq c
$$

\section{First round:}

At the first stage, in order to monopolize the industry in the following stage, the firm 1 has to buy one firm. To buy the other one, it has to pay an infinite and discounted flow of triopoly profit. As the game is dynamic, the dominant firm can spread his takeovers over several rounds. Consequently, the hold up mechanism of the static game disappears. Moreover, when the firm 1 buys a firm, it gives up his infinite and discounted flow of triopoly profit. It is his opportunity cost. Nevertheless, it will earn a duopoly profit instead (proof in 
appendix B):

$$
\pi_{1}^{2}\left(c_{1}, c\right)-\frac{\pi_{2}^{3}\left(c_{1}, c\right)}{(1-\delta)}+\delta\left[\frac{\pi_{1}^{1}\left(c_{1}\right)}{(1-\delta)}-\frac{\pi_{1}^{2}\left(c_{1}, c\right)}{(1-\delta)}\right] \geq \frac{\pi_{1}^{3}\left(c_{1}, c\right)}{(1-\delta)}
$$

(6) holds if (7) is checked:

$$
c \geq c^{*}\left(c_{1}, \delta\right)
$$

with

$$
c^{*}\left(c_{1}, \delta\right)=\frac{1}{2} \frac{13 c_{1}+22 \delta c_{1}+1-2 \delta}{10 \delta+7}
$$

Lemma 2 Let $c_{1} \in[0,1]$ and $\delta \in[0,1]$, then it always exists a $c \in[0,1]$ verifying $C^{*}\left(c_{1}, \delta\right) \leq C \leq \frac{1+c_{1}}{2}$.

Proof. As seen in the previous section, the same sustainable industry conditions must be checked. Therefore, we establish that $\forall c_{1} \in[0,1]$ and $\forall \delta \in[0,1]$, $\frac{11}{10} c_{1}-\frac{1}{10} \leq c^{*}\left(c_{1}, \delta\right) \leq \frac{1+c_{1}}{2}$. Then, we can state that it always exists $c \in[0,1]$ verifying $c^{*}\left(c_{1}, \delta\right) \leq c \leq \frac{1+c_{1}}{2} \leq 1$.

As the first round condition is the most restrictive, we can state the following proposition:

Proposition 2 Let $c \in[0,1], \quad c_{1} \in[0,1]$ and $\delta \in[0,1]$, then $a$ monopolization path of a three-firm industry exists if and only if $c \geq c^{*}\left(c_{1}, \delta\right)$.

Here, we show that monopolization of a three-firm industry is possible for every $\delta \in[0,1]$, provided that the cost heterogeneity is large enough . In the 
symmetric case, that is for $c_{1}=c$, we find, like Kamien and Zang (1993), that monopolization of a three-firm industry is possible if $\delta \in\left[\frac{1}{2}, 1\right]$.

Note that $\forall \delta \in[0,1], \forall c_{1} \in[0,1], \frac{\partial c^{*}\left(c_{1}, \delta\right)}{\partial \delta} \leq 0$. This means that, the larger the discount factor is, the larger the monopolization possibilities are. ${ }^{8}$ Indeed, future profits are more valued while acquisition payments are spread over the time.

Moreover, as the owner of the dominant firm does not have to monopolize the industry in an only one round, other owners cannot ask the duopoly profit for their firms: this fall of acquisition cost explains the monopolization facilities in a dynamic context.

Note that, if $c=c_{1}$, monopolization is feasible if and only if $\delta \in\left[\frac{1}{2} ; 1\right]$. Therefore, we find again the result of Kamien and Zang (1993).

\subsection{With a four-firm industry:}

In this industry configuration, there are several monopolization paths, but we can prove that monopolization is easier with three rounds.

Thus, we study this path. Let us solve by the same way:

The conditions of the third and second stage are respectively the same than

${ }^{8} \underline{c}\left(3, c_{1}\right) \geq c^{*}\left(c_{1}, \delta\right)$ if and only if $\delta \geq 1 / 22$. Therefore, there are more monopolization possibilities in dynamic games than in static ones if $\delta \geq 1 / 22$. 
the conditions of the second and first stage in the appendix B. But there is another stage in which another firm is previously bought (cf. the proof in appendix $\mathrm{A}$ and $\mathrm{B})$.

Third round: the first owner buys the last firm:

$$
\frac{\pi_{1}^{1}\left(c_{1}\right)}{(1-\delta)}-\frac{\pi_{2}^{2}\left(c_{1}, c\right)}{(1-\delta)} \geq \frac{\pi_{1}^{2}\left(c_{1}, c\right)}{(1-\delta)}
$$

(8) holds if (9) is checked:

$$
\frac{11}{10} c_{1}-\frac{1}{10} \leq c
$$

Second round: the first owner buys another firm:

$$
\pi_{1}^{2}\left(c_{1}, c\right)-\frac{\pi_{2}^{3}\left(c_{1}, c\right)}{(1-\delta)}+\delta\left[\frac{\pi_{1}^{1}\left(c_{1}\right)}{(1-\delta)}-\frac{\pi_{1}^{2}\left(c_{1}, c\right)}{(1-\delta)}\right] \geq \frac{\pi_{1}^{3}\left(c_{1}, c\right)}{(1-\delta)}
$$

(10) holds if (11) is checked:

$$
\frac{1}{2} \frac{13 c_{1}+22 \delta c_{1}+1-2 \delta}{10 \delta+7} \leq c
$$

First round: the first owner buys one firm:

At the first stage, in order to monopolize the industry in the following stage, the first firm has to buy one firm. To buy the other, it has to pay an infinite and discounted profit flow of a single firm in a four-firm industry. Indeed, the hold up mechanism of the static game does not exist. Moreover, by purchasing a firm, the firm 1 gives up his infinite and discounted profit flow of single firm in a four-firm industry. Nevertheless, it will earn a triopoly profit instead (proof in the appendix C):

$$
\pi_{1}^{3}\left(c_{1}, c\right)-\frac{\pi_{2}^{4}\left(c_{1}, c\right)}{(1-\delta)}+\delta\left[\pi_{1}^{2}\left(c_{1}, c\right)-\frac{\pi_{2}^{3}\left(c_{1}, c\right)}{(1-\delta)}\right]
$$




$$
+\delta^{2}\left[\frac{\pi_{1}^{1}\left(c_{1}\right)}{(1-\delta)}-\frac{\pi_{1}^{2}\left(c_{1}, c\right)}{(1-\delta)}\right] \geq \frac{\pi_{1}^{4}\left(c_{1}, c\right)}{(1-\delta)}
$$

(12) holds if (13) is checked:

$$
c \geq \tilde{C}\left(c_{1}, \delta\right)
$$

with

$$
\tilde{c}\left(c_{1}, \delta\right)=\frac{1100 \delta^{2} c_{1}+650 \delta c_{1}+423 c_{1}-100 \delta^{2}+50 \delta+63}{2\left(243+500 \delta^{2}+350 \delta\right)}
$$

Because of the lemma 2 and because $\forall c_{1} \in[0,1]$ and $\forall \delta \in[0,1]$, $\frac{11}{10} C_{1}-\frac{1}{10} \leq \frac{1}{2} \frac{13 c_{1}+22 \delta c_{1}+1-2 \delta}{10 \delta+7} \leq \tilde{C}\left(c_{1}, \delta\right) \leq \frac{1+c_{1}}{2}$, we can state that it always exists a $c \in[0,1]$ verifying $\tilde{c}\left(c_{1}, \delta\right) \leq c \leq \frac{1+c_{1}}{2}$.

As the first round condition is the most restrictive, we can state the following proposition:

Proposition 3 Let $c \in[0,1], \quad c_{1} \in[0,1]$ and $\delta \in[0,1]$, then $a$ monopolization path of a four-firm industry exists if and only if $c \geq \tilde{c}\left(c_{1}, \delta\right)$.

Note that $\forall \delta \in[0,1], \forall c_{1} \in[0,1], \frac{\partial \tilde{c}\left(c_{1}, \delta\right)}{\partial \delta} \leq 0$. This implies that, the larger the discount factor is, the larger the monopolization possibilities are. We state the following inequality:

$$
c \geq \tilde{c}\left(c_{1}, \delta\right)
$$

The expression (14) implies that monopolization of a four symmetric firms industry is not possible. We can also say that there are more monopolization 
possibilities in dynamic games than in static ones. Indeed, $\tilde{c}\left(c_{1}, \delta\right) \leq \underline{c}\left(4, c_{1}\right)$.

These remarks are in line with the intuitions mentioned for three-firm industries, with the actualization effect and the dynamic effect.

\section{Conclusion:}

In this paper, we have shown that firms' heterogeneity increases the incentives to merge. Since the best method to value these incentives is to make endogenous merger decisions, we have built a model in which owners' decisions are taken into account.

To simplify the analysis, we focused on the extreme case where merger leads to monopolization.

Our results differ from Kamien and Zang (1990 and 1993). Indeed, these authors showed that large industries cannot be monopolized. Introducing a large enough cost heterogeneity, we have shown that monopolization is feasible for all industry sizes. Moreover, monopolization is easier if the game is a dynamic one and especially if the discount factor is high. To reach this conclusion, we provided two illustrations, for three and four firm-industry because in dynamic, the n-firm generalization is too complex. This result supports the "takeover waves" explanation of Fauli-Oller (2000) based on cost asymmetries. Moreover, the following intuition explains it: the monopoly profit is more sensitive to a fall in production cost than oligopoly profit.

Our results are also in contradiction with Gowrisankaran and Holmes (2004). They show that a large competitive industry stays a large competitive 
industry. No merger appears in this case. On the contrary, our model shows that large industries can be monopolized if the cost heterogeneity is large enough.

Nevertheless, extensions of this line of research are necessary to take into account data neglected in our model. These extensions should include several purchasers in these games, take into account decentralized games in which firms are individually managed, and at last, find oligopoly equilibria to these games, especially if collusion is possible. The aim of these studies would be to provide tools to anticipate concentration processes. Another research should be developed in parallel: a welfare analysis restricted to the cases of industry in which concentration processes are possible.

The final aim of this research is to identify industries in which monopolization is not possible. Thus, authorities could concentrate on the other industries in order to determine the monopolization processes which could be detrimental to the global welfare. Moreover, as firms supposed to monopolize the industries are the most efficient, the possibilities of monopolization decreasing welfare are limited.

\section{Acknowledgements}

I wish to thank Rabah Amir, Simon Andesson, Edmond Baranes and Wilfried Sand-Zantman for their helpful comments. 


\section{Appendix A}

Given the individual marginal costs $c_{i}$ and the linear inverse demand $P(Q)=1-Q$, the firm profits in the n-firm problem are given by Letho and Tombak (1998):

$$
\frac{\left(1-n c_{i}+\sum_{j \neq i} c_{j}\right)^{2}}{(n+1)^{2}}
$$

We can give, concerning the second round, the monopoly profit of the first firm:

$$
\pi_{1}^{1}\left(c_{1}\right)=\frac{\left(1-c_{1}\right)^{2}}{4}
$$

We can establish the opportunity cost of the firm 1 (profit realized by the first firm if it buys no firm):

$$
\pi_{1}^{2}\left(c_{1}, c\right)=\frac{\left(1-2 c+c_{1}\right)^{2}}{9}
$$

The acquisition cost of a firm by the firm 1 is:

$$
\pi_{2}^{2}\left(c_{1}, c\right)=\frac{\left(1-2 c_{1}+c\right)^{2}}{9}
$$

Hence, the second stage monopolization condition is (by actualizing infinite flow of profits):

$$
\frac{\pi_{1}^{1}\left(c_{1}\right)}{(1-\delta)}-\frac{\pi_{2}^{2}\left(c_{1}, c\right)}{(1-\delta)} \geq \frac{\pi_{1}^{2}\left(c_{1}, c\right)}{(1-\delta)}
$$

which is equivalent to:

$$
\frac{\left(1-c_{1}\right)^{2}}{4(1-\delta)}-\frac{\left(1-2 c+c_{1}\right)^{2}}{9(1-\delta)} \geq \frac{\left(1-2 c_{1}+c\right)^{2}}{9(1-\delta)}
$$




\section{Appendix B}

As in the appendix A:

We can determinate, concerning the first round, the duopoly profit of the firm 1:

$$
\pi_{1}^{2}\left(c_{1}, c\right)=\frac{\left(1-2 c_{1}+c\right)^{2}}{9}
$$

We can give the opportunity cost of the firm 1 (the profit realized by the first firm if it buys no firm):

$$
\pi_{1}^{3}\left(c_{1}, c\right)=\frac{\left(1-3 c_{1}+2 c\right)^{2}}{16}
$$

We can establish the acquisition cost of a firm by the firm 1 :

$$
\pi_{2}^{3}\left(c_{1}, c\right)=\frac{\left(1-2 c+c_{1}\right)^{2}}{16}
$$

Finally, to monopolize the industry, the first firm has to buy the remaining firm at the second stage The monopolization condition of second period has to take into account this future buying (by actualizing infinite flow of profits when it is necessary):

$$
\pi_{1}^{2}\left(c_{1}, c\right)-\frac{\pi_{2}^{3}\left(c_{1}, c\right)}{(1-\delta)}+\delta\left[\frac{\pi_{1}^{1}\left(c_{1}\right)}{(1-\delta)}-\frac{\pi_{1}^{2}\left(c_{1}, c\right)}{(1-\delta)}\right] \geq \frac{\pi_{1}^{3}\left(c_{1}, c\right)}{(1-\delta)}
$$

which is equivalent to:

$$
\begin{gathered}
\frac{\left(1-2 c_{1}+c\right)^{2}}{9}-\frac{\left(1-2 c+c_{1}\right)^{2}}{16(1-\delta)} \\
+\delta\left[\frac{\left(1-c_{1}\right)^{2}}{4(1-\delta)}-\frac{\left(1-2 c+c_{1}\right)^{2}}{9(1-\delta)}\right] \geq \frac{\left(1-3 c_{1}+2 c\right)^{2}}{16(1-\delta)}
\end{gathered}
$$




\section{Appendix C}

Now, concerning the first round, the triopoly profit of the firm 1 is:

$$
\pi_{1}^{3}\left(c_{1}, \quad c\right)=\frac{\left(1-3 c_{1}+2 c\right)^{2}}{16}
$$

About the opportunity cost of the firm 1 (the profit realized by the first firm if it buys no firm), it is given by:

$$
\pi_{1}^{4}\left(c_{1}, c\right)=\frac{\left(1-4 c_{1}+3 c\right)^{2}}{25}
$$

Finally, the acquisition cost of a firm by the firm 1 is:

$$
\pi_{2}^{4}\left(c_{1}, c\right)=\frac{\left(1-2 c+c_{1}\right)^{2}}{25}
$$

Finally, as to monopolize the industry, the first firm has to buy another firm at the second stage and the remaining one in the third stage, the monopolization condition of third period has to take into account these future buying (by actualizing infinite flow of profits when it's necessary):

$$
\begin{gathered}
\pi_{1}^{3}\left(c_{1}, c\right)-\frac{\pi_{2}^{4}\left(c_{1}, c\right)}{(1-\delta)}+\delta\left[\pi_{1}^{2}\left(c_{1}, c\right)-\frac{\pi_{2}^{3}\left(c_{1}, c\right)}{(1-\delta)}\right] \\
+\delta^{2}\left[\frac{\pi_{1}^{1}\left(c_{1}\right)}{(1-\delta)}-\frac{\pi_{1}^{2}\left(c_{1}, c\right)}{(1-\delta)}\right] \geq \frac{\pi_{1}^{4}\left(c_{1}, c\right)}{(1-\delta)}
\end{gathered}
$$

which is equivalent to:

$$
\begin{gathered}
\frac{\left(1-3 c_{1}+2 c\right)^{2}}{16}-\frac{\left(1-2 c+c_{1}\right)^{2}}{25(1-\delta)}+\delta\left[\frac{\left(1-2 c_{1}+c\right)^{2}}{9}-\frac{\left(1-2 c+c_{1}\right)^{2}}{16(1-\delta)}\right] \\
+\delta^{2}\left[\frac{\left(1-c_{1}\right)^{2}}{4(1-\delta)}-\frac{\left(1-2 c+c_{1}\right)^{2}}{9(1-\delta)}\right] \geq \frac{\left(1-4 c_{1}+3 c\right)^{2}}{25(1-\delta)}
\end{gathered}
$$




\section{References}

[1] Charléty, P., S. Souam, (2002) "Analyse Economique des Fusions Horizontales," Revue Française d'Economie, Vol. 17, N², pp. 37-68.

[2] Fauli-Oller, R. (2000) "Takeover Waves," Journal of Economics and Management Strategy, Vol. 9, $\mathrm{N}^{\circ}$ 2, pp. 189-210.

[3] Fridolfsson, S., J. Stennek, (2005) "Hold-up of Anti-Competitive Mergers," International Journal of Industrial Organization, Vol. 23, issues 910, pp753-75.

[4] Gorwisankaran, G., and T. J. Holmes, (2004) "Mergers and the evolution of industry concentration : results from the dominant-firm model," RAND Journal of Economics, Vol. 35, Issue 3, p561, 22p.

[5] Horn, H., L. Persson, (2001a), "Endogenous Mergers in Concentrated Markets," International Journal of Industrial Organization, Vol. 19, Issue 8, pp1213-44.

[6] Kamien, M., I. Zang, (1990) "The Limits of Monopolization Through Acquisition," Quarterly Journal of Economics, Vol. 105, pp. 465-99.

[7] Kamien, M., I. Zang, (1993) "Monopolization by Sequential Acquisition," Journal of Law, Economics and Organization, Vol. 9, $\mathrm{N}^{\circ}$ 2, pp. 205-229.

[8] Letho, P., M. Tombak, (1998) "Consolidation and the Sequence of Acquisitions to Monopoly," Mimeo.

[9] Salant, S. W., S. Switzer, and R. J. Reynolds, (1983) "Losses from Horizontal Merger : The Effects of an Exogenous Change in Industry Structure on Cournot-Nash Equilibrium", 93, Quarterly Journal of Economics, pp. 185- 


\section{9.}

[10] Williamson, O. (1968) "Economics as an Antitrust Defense: The Welfare Trade-offs", American Economic Review, Vol. 58, pp. 18-36. 